https://www.amerabra.org; https://fspu.uitm.edu.my/cebs; https://www.emasemasresources.com/ AMEABRA International Virtual Conference on Environment-Bahaviour Studies, $2^{\text {nd }}$ Series

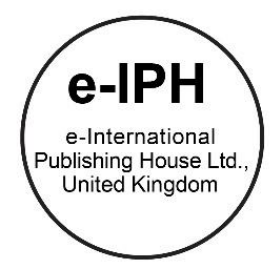

\title{
Employees' Job Satisfaction and Performance through Working from Home during the Pandemic Lockdown
}

\author{
Rugayah Hashim¹, Alfina Bakar², Ismayaza Noh³, Hanim Azura Mahyudin ${ }^{4}$ \\ ${ }^{1}$ Research \& Innovation Division, Universiti Teknologi MARA Cawangan Selangor, Puncak Alam, Malaysia \\ ${ }^{2}$ Human Resource Department, Universiti Teknologi MARA, Shah Alam, Malaysia \\ ${ }^{3}$ Faculty of Hotel \& Tourism Management, Universiti Teknologi MARA Cawangan Selangor, Puncak Alam, Malaysia \\ ${ }^{4}$ Human Resource \& Development Division, Universiti Teknologi MARA Cawangan Selangor, Puncak Alam, Malaysia
}

Email of All Authors: guy73106@yahoo.com, alfina@uitm.edu.my, ismay147@uitm.edu.my, hanim946@uitm.edu.my Tel of 1 st Author: +60332584333

\begin{abstract}
The pandemic lockdown provided the impetus for working from home or telework. The survey objective was to gauge the employees' job satisfaction and performance while working from home. Responses from 503 (80.9\%) administrative staff from Universiti Teknologi MARA Cawangan Selangor, Malaysia, were analyzed. The findings indicated that $87.1 \%$ were satisfied with working from home; however, the work performance, measured through the availability of ICT peripherals, showed a dismaying $53.7 \%$. The implications from the findings require university administrators to reassess the policy for working from home, that is, only employees with adequate ICT equipment can be allowed to telework.
\end{abstract}

Keywords: work from home, telework, job satisfaction, work performance

eISSN: 2398-4287C 2020. The Authors. Published for AMER ABRA cE-Bsby e-International Publishing House, Ltd., UK. This is an open access article under the CC BYNC-ND license (http://creativecommons.org/licenses/by-nc-nd/4.0/). Peer-review under responsibility of AMER (Association of Malaysian Environment-Behaviour Researchers), ABRA (Association of Behavioural Researchers on Asians), and cE-Bs (Centre for Environment-Behaviour Studies), Faculty of Architecture, Planning \& Surveying, Universiti Teknologi MARA, Malaysia.

DOI: https://doi.org/10.21834/ebpj.v5i15.2515

\subsection{Introduction}

The worldwide, pandemic lockdown caused all employees to work from home. Consequently, the internet has become the lifeline for most communication modes among everyone affected by the lockdown. After the lockdown, should employees be allowed to work from home? After the lockdown, should employees be allowed to work from home? Online transactions have also shown a substantial, factorial increase as employees were forced into telework or remote working (Steward, 2000). For some developed countries, teleworking for public sector employees or government servants have been practiced for years because of its perceived benefits (Kwon \& Jeon, 2020). The question is, does the perceived benefits extend to employees in developing countries during the lockdown period? Nonetheless, job satisfaction when working from home is essential for the employee and the organization's administrators. Therefore, the paper aims to provide empirical evidence on the feasibility of working from home for university administrative staff at Universiti Teknologi MARA Cawangan Selangor (UCS). The months-long pandemic lockdown required all employees in Malaysia to adjust to remote working or working from home. For the university administrative staff, the challenges of working remotely during the lockdown period require the department heads to assess their work satisfaction, performance, and productivity level.

For Malaysia, it has been more than seven months since the first pandemic lockdown was announced by the Prime Minister in March 2020. Being locked down in one's home required all Malaysian employees to adjust to remote working or working from home. For the university administrative staff, the challenges of working remotely during the lockdown period require the department heads to assess their work satisfaction and productivity level. To reiterate, similar to most government's decision on imposing lockdowns to contain the COVID-19 pandemic, citizens' movements were restricted to their respective dwellings. Anyway, the lockdown has led to all employees at UiTM Cawangan Selangor to work remotely as some are at their house while others went back to their home towns. After the pandemic lockdown, there have been inquiries about whether employees should continue to work remotely. The increased interest in working from 
home options before the lockdown was rare (Baker, Avery, \& Crawford, 2007). This study investigates the viability in which the continuation of remote work initiatives can be better supported by the fulfillment of quality work done and the satisfaction of working from home.

\subsection{Background of Study}

When the rise in coronavirus disease 2019 (COVID-19) cases rose significantly in March 2020, the Malaysian government announced the first lockdown period, the Movement Control Order (MCO), from March 16-31, 2020 (Tang, 2020). Further measures to contain the pandemic resulted in additional lockdown periods of varying phases. Nonetheless, the first three phases of the movement control order mandated all people living in Malaysia to be restricted within the home environment (Azlan, Hamzah, Sern, Ayub, \& Mohamad, 2020). The brief timeline of the lockdowns is shown in Table 1.0; however, as of the writing of this paper, Malaysia has imposed the recovery and conditional Movement Control Orders with the latest one ending on December 31, 2020.

Table 1.0 - Brief timeline of Malaysia's Covid-19 Movement Control Orders (Source: ISIS, 2020)

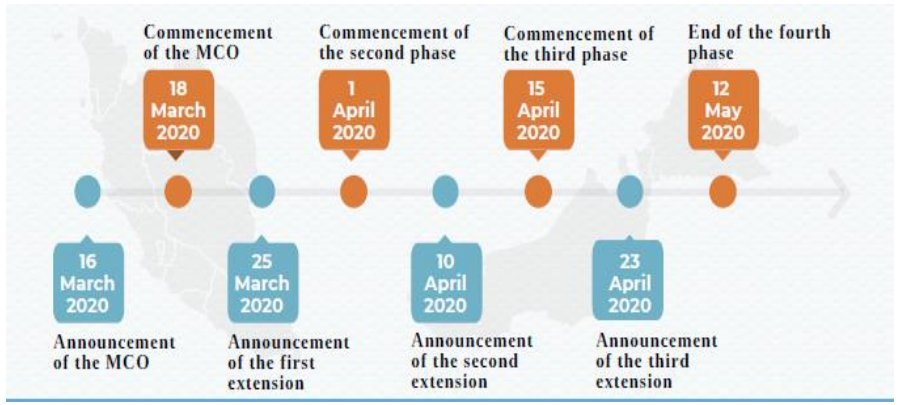

\subsection{Purpose of the study}

The purpose of this study was to determine the administrative staff's perceptions of working from home during and post-movement control orders (MCO) to contain the Covid-19 pandemic. The survey findings were expected to provide empirical support for the university administrators to continue working from home or otherwise during or after the pandemic.

\subsection{Objective of the study}

In line with the purpose of the study, the objectives of this investigation were to determine the job satisfaction level and the indicators for performance among UCS's administrative staff at Universiti Teknologi MARA, Selangor

\subsection{Significance of the study}

The study is significant for the university management to decide on continuing the work from home alternative for the administrative staff. However, the quantity and quality of work produced must fulfill the employees' set targets. Moreover, the team who works from home must complete the daily logbook and submit that to their respective superiors. With the new normal, the importance of the work environment is crucial for employees' well-being in meeting organizational goals.

\subsection{Literature Review}

Over the past decades, office workers' tasks were done using computers. For some jobs such as journalism, working from home was a popular choice. However, for other jobs such as in construction, the nature of the manual and hard labor required is not possible (N. A. Saludin \& Hassan, 2012). option to work from home is not viable. Hence, the rest of the literature will discuss the different terminologies on working from home and the debates on this option to continue the policy for today's office workers after the pandemic lockdown. The other vocabularies are teleworking, telecommuting, homeworking, and working from home (ibid).

\subsection{Overview of Telework, Telecommuting, or Remote Working}

Teleworking or telecommuting is not new. Telecommuting (as coined by Jack Niles) has been around since 1972 (van Meel, 2011 ). Employees throughout the world were allowed to work from home or telework during the lockdown periods. With the outbreak of the Covid-19 pandemic, governments instituted nation-wide lockdowns. Many countries initiated lockdowns to contain the Covid-19 epidemic (Feng \& Savani, 2020; Zhang, Wang, Rauch, \& Wei, 2020), including Malaysia. Employees working in non-essential jobs were ordered to stay at home at all times, allowing only a small percentage of employees in essential services (e.g., food, healthcare, delivery) to go to work (Zhang et al., 2020). In Malaysia, all schools and universities were closed, and online learning became the new normal. However, for the universities' administrative staff, such as Universiti Teknologi MARA, work-from-home policies for all employees were instituted, and work was completed remotely. Regardless of the situation, teleworking or remote working gave administrative staff the work continuance but with a different location. 
According to Wheatley (2012), home-based teleworking reported higher satisfaction levels, especially for working mothers. The spillover of employees working from home will affect their families and, inherently, job satisfaction (llies, Wilson, \& Wagner, 2009). gave telecommuters the option of working from home to accommodate personal or family needs (Hill \& Fellows, 2014).

Ever since President Barack Obama signed the TEA on December 9, 2010, the enactment has been a popular public management work option for the United States' federal government employees (Kwon \& Jeon, 2020). However, the same cannot be applied to Malaysia's civil servants, as opined by N. Saludin, Karia, and Hassan (2013). Though Malaysia's Vision 2020, it is expected that telework among the public sector employees will be part and parcel of a digital society practice that is yet to be. The unprecedented pandemic lockdown, however, has resulted in all employees undertaking telework. According to (Wheatley, 2012), home-based teleworking reported higher satisfaction levels, especially for working mothers. The spillover of employees working from home will affect their families and, inherently, job satisfaction (llies et al., 2009). gave telecommuters the option of working from home to accommodate personal or family needs (Hill \& Fellows, 2014).

Ever since President Barack Obama signed the TEA on December 9, 2010, the enactment has been a popular public management work option for the United States' federal government employees (Kwon \& Jeon, 2020). However, the same cannot be applied to Malaysia's civil servants, as opined by N. Saludin et al. (2013). Through Malaysia's Vision 2020, it is expected that telework among the public sector employees will be part and parcel of a digital society practice, but that is yet to be. The unprecedented pandemic lockdown, however, has resulted in all employees undertaking telework.

\subsection{Job satisfaction and subjective well-being}

For most employees, job satisfaction is of the utmost importance. Alongside job satisfaction, other determinants of subjective wellbeing from work prioritize the employed individuals (Azizan \& Mahmud, 2018). When working from home or teleworking, the basic human needs are fulfilled (Diener, Diener, \& Diener, 1995), particularly so during the pandemic lockdowns where the family's health safety is of utmost concern.

\subsection{Productivity and Performance in Telework}

Allowing employees to work from home (or telework) requires the element of trust for the employers. However, during the pandemic lockdown periods, teleworking is the obvious choice. Measuring productivity in telework and job satisfaction is positively correlated (Kazekami, 2020). Nevertheless, life satisfaction should also not be confused with job satisfaction (ibid). Telework factors, as mentioned by Nakrosiene, Buciuniene, and Gostautaite (2019), involved overall satisfaction, perceived advantages of telework, career opportunities, and self-reported productivity. Their findings indicated that reduced communication with co-workers, superior's trust and support, the suitability of the working place at home were the most critical factors impacting working from home outcomes. Coincidentally, these are similar elements undertaken for this study. So long as the Covid-19 pandemic persists, working from home to lessen people's mobility is the best option for all organizations. In doing so, it is expected that teleworking will result in higher levels of worker satisfaction and productivity, leading to increased income levels (Gallardo \& Whitacre, 2018), hence continuing to impact local economies.

\subsection{Methodology}

\subsection{Scope of the study}

The scope of the study was institutional in manner; that is, only the administrative staff working at UCS (Universiti Teknologi MARA Cawangan Selangor) were the identified population sample ( $\mathrm{N}=622)$.

\subsection{Data collection}

The quantitative method of this institutional study formed the practicality of the research project. The instrument used to collect primary data was an online questionnaire designed on Google Form. The census sampling method was used where the population sample was 622 administrative staff at the four campuses under UCS. Additionally, all the administrative staff from the 15 departments are located at the four campuses, which were Puncak Alam, Puncak Perdana, Dengkil, and Sungai Buloh. The administrative staff was contacted via department WhatsApp groups providing them with a link to the e-survey. The response rate was 514 , or $85.7 \%$.

\subsection{Theory and Data Analysis}

Based on the literature reviewed with almost similar examination areas, the study's underpinning theories were organizational behavior (Ollo-Lopez, Goni-Legaz, \& Erro-Garces, 2020) and human resource management (Peters, Ligthart, Bardoel, \& Poutsma, 2016). The data analyses consisted of descriptive statistics, interpreting the data in the form of graphs, and describing the illustrations.

\subsection{Data Interpretation}

From the data analyses, the results were interpreted accordingly. The interpretations from the frequencies and percentages were later expanded by research objectives and the discussion section.

\subsection{Findings}

4.1 Demographics

Firstly, the demographic variables are shown in Table 1. For the gender breakdown, there are more males (58.8\%) respondents than 
there are female (41.2\%). Also, the highest number of respondents were from the age bracket of $30-39$ years.

\begin{tabular}{lll} 
& Table 1.Gender breakdown of respondents \\
\hline Demographic variables & Frequency & Percentage \\
\hline Gender: Male & 302 & 58.8 \\
Female & 212 & 41.2 \\
& & \\
Age: $20-29$ years & 40 & 7.8 \\
30-39 years & 276 & 53.7 \\
40-49 years & 135 & 26.2 \\
$50-60$ years & 63 & 12.3 \\
\hline
\end{tabular}

\subsection{Job satisfaction analytics}

The job satisfaction analytics were derived from the feedbacks, as indicated in Fig. 1, where $87.1 \%$ are satisfied with working at home, but $12.9 \%$ were not happy with working from home.

Fig. 1: Job satisfaction from working at home

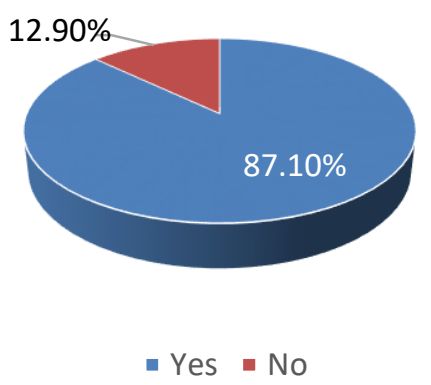

\subsection{Work performance analytics}

The work performance was measured based on the availability of workspace at home (Fig. 2) and the availability of information and computer technologies (ICT) at home (Fig. 3). ICT will also include internet access. From the pie chart in Fig. 2, 64.4\% of the respondents have a good workspace at home, while $35.6 \%$ do not. Meanwhile, $64.6 \%$ of the respondents have the necessary ICT peripherals to work at home, but $35.4 \%$ do not have adequate ICT to continue working from home. The quantity and quality of work were also measured from the logbooks, as shown in Table 2. As evidenced, only $82.3 \%$ of the administrative staff updated their logs when working from home. On the contrary, 91 employees did not complete their logbooks, and this is a major concern for the university management. Discussions on these findings will be done in the next section.

Fig. 2. Availability of workspace at home; Fig. 3. Availability of ICT at home
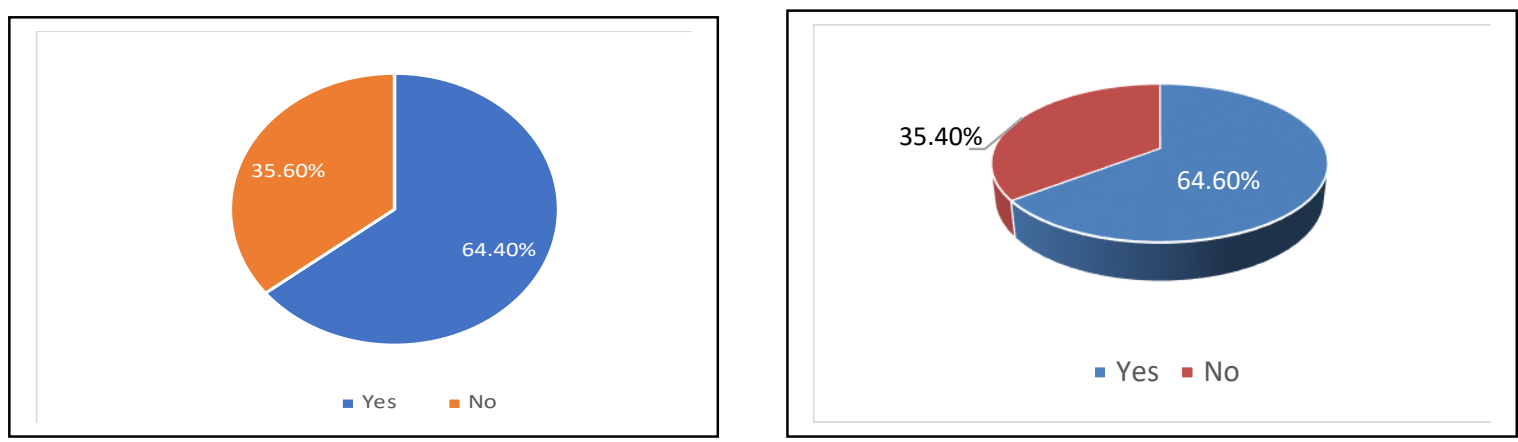

Table 2. Completion of logbook while working from home

\begin{tabular}{lll}
\hline Complete logbook when working from home? & Frequency & Percentage \\
\hline Yes & 423 & 82.3 \\
No & 91 & 17.7 \\
& & \\
\hline
\end{tabular}




\subsection{Discussions}

The findings revealed the extent of UiTM Cawangan Selangor's administrative staffs' preference for working from home. The results fulfilled the first research objective. The underlying reasons for wanting to work from home were personal and, family needs as shown in the literature. Other elements such as travel time, opportunity costs and home comfort factor into the preference for working from the house. For the second objective, employees allowed to work from home should update their logbooks and submit that to their superiors regularly. Completing and detailing the work done at home are important tasks that evidence integrity and the fulfillment of one's key performance indicators. The practice of integrity is essential for any organization in its work from home policy. There are pros and cons to approving a mixed working schedule for the administrative staff. Both employees and employers will practice the new normal in the work-life balance due to greater autonomy and gratitude for employees (Anderson \& Kelliher, 2020) particularly those with young families.

Another one of the study's implications is that university management should consider the positive and negative outcomes of allowing the administrative staff to continue working from home after the pandemic lockdown. The same recommendation was made by Anderson and Kelliher (2020). The main points to consider would be the quality of work produced and in keeping with the staff's key performance indicators. From Table 2, 91 employees did not complete their logbooks which by right, should disqualify them from continuing to work from home. The administrators have emphasized that keeping daily logs is a mandatory requirement where non-compliance to this policy will revoke the telework option for the employee. In addition, the revision of the flexible working policies should not gender discriminate, especially with childcare provision as the most important reason for working from home for female employees. The wellbeing of the employees should continue to be a priority for university management. Concentrated efforts in containing the COVID-19 pandemic requires fewer people movement; hence, the option to work from should be supported, particularly for employees with young families. The unprecedented pandemic lockdowns have created a global VUCA (volatile, uncertain, complex, ambiguous) environment which challenges the organization's management (Ochoa, Lepeley, \& Essens, 2019) but the employees' wellbeing should continue to be a priority. The opposite is also true. The employee needs to comply with the university policies and fulfill their KPI diligently.

\subsection{Limitations of Study}

The survey project undertaken was an institutional study; that is, the respondents are from one organization; therefore, the applications to practice are limited to public university administrators. Moreover, the sample size should be increased to include other administrative staff from other campuses. Also, the survey instrument's design consisted of close-ended statements where for the next investigation, it is recommended that the responses be recorded on a scale of one to five.

\subsection{Conclusion and Recommendations}

In conclusion, UCS should consider the work from home alternative for the administrative staff but, the segment of those allowed to do so would depend on their job scope. The clerical staff would be the first choice for the work from home option but the employees do need to be physically present at the office from time to time as deemed by the superior. On the other hand, the percentage of those that did not complete their daily logbooks is a major concern since there is no evidence of actual work done. The non-completion of the logbook should affect the employees' annual performance evaluation. It is also recommended that UCS's administrative staff under the reskilling of ICT-based training as working from home require heavy usage of telecommunication equipment. The employees also need to have adequate ICT equipment at home to assist with their various job scope. When administrative staff can work remotely while ensuring that their productivity level, work performance, and work quality are maintained, the university executive administration should consider this alternative as the new normal for the relevant departments.

\section{Acknowledgements}

We would like to thank Universiti Teknologi MARA Cawangan Selangor (UCS) for funding the publication. We would also like to thank the staff at UCS for their cooperation in responding to the survey.

\section{Paper Contribution to Related Field of Study}

This paper contributes to the field of human resource management and the work environment.

\section{References}

dAnderson, D., \& Kelliher, C. (2020). Enforced remote working and the work-life interface during lockdown. Gender in Management: An International Journal, ahead-ofprint(ahead-of-print). doi:10.1108/GM-07-2020-0224

Azizan, N. H., \& Mahmud, Z. (2018). Determinants of Subjective Well-Being: A Systematic Review. Environment-Behaviour Proceedings Journal, 3(7), 135-141. doi:10.21834/e-bpj.v3i7.1228

Azlan, A. A., Hamzah, M. R., Sern, T. J., Ayub, S. H., \& Mohamad, E. (2020). Public knowledge, attitudes and practices towards COVID-19: A cross-sectional study in Malaysia. Plos One, 15(5). doi:10.1371/journal.pone.0233668

Baker, E., Avery, G. C., \& Crawford, J. (2007). Satisfaction and perceived productivity when professionals work from home. Research \& Practice in Human Resource Management. 
Diener, E., Diener, M., \& Diener, C. (1995). FACTORS PREDICTING THE SUBJECTIVE WELL-BEING OF NATIONS. Journal of Personality and Social Psychology, 69(5), 851-864. doi:10.1037/0022-3514.69.5.851

Feng, Z., \& Savani, K. (2020). Covid-19 created a gender gap in perceived work productivity and job satisfaction: implications for dual-career parents working from home. Gender in Management: An International Journal, ahead-of-print(ahead-of-print). doi:10.1108/GM-07-2020-0202

Gallardo, R., \& Whitacre, B. (2018). 21st century economic development: Telework and its impact on local income. Regional Science Policy and Practice, 10(2), 103123. doi:10.1111/rsp3.12117

Hill, E. J., \& Fellows, K. J. (2014). Telework. In A. C. Michalos (Ed.), Encyclopedia of Quality of Life and Well-Being Research (pp. 6607-6609). Dordrecht: Springer Netherlands.

llies, R., Wilson, K. S., \& Wagner, D. T. (2009). The spillover of daily job satisfaction onto employees' family lives: The facilitating role of work-family integration. Academy of Management Journal, 52(1), 87-102.

Kazekami, S. (2020). Mechanisms to improve labor productivity by performing telework. Telecommunications Policy, 44(2). doi:10.1016/j.telpol.2019.101868

Kwon, M., \& Jeon, S. H. (2020). Do Leadership Commitment and Performance-Oriented Culture Matter for Federal Teleworker Satisfaction With Telework Programs? Review of Public Personnel Administration, 40(1), 36-55. doi:10.1177/0734371x18776049

MDBC. (2020). MCO Updates. Retrieved from https://www.mdbc.com.my/mco-updates/?cn-reloaded=1

Nakrosiene, A., Buciuniene, I., \& Gostautaite, B. (2019). Working from home: characteristics and outcomes of telework. International Journal of Manpower, 40(1), 87 101. doi:10.1108/ijm-07-2017-0172

Ochoa, P., Lepeley, M.-T., \& Essens, P. (2019). Wellbeing for sustainability in the global workplace. London: Routledge.

Ollo-Lopez, A., Goni-Legaz, S., \& Erro-Garces, A. (2020). Home-based telework: usefulness and facilitators. International Journal of Manpower. doi:10.1108/ijm-022020-0062

Peters, P., Ligthart, P. E. M., Bardoel, A., \& Poutsma, E. (2016). 'Fit' for telework'? Cross-cultural variance and task-control explanations in organizations' formal telework practices. International Journal of Human Resource Management, 27(21), 2582-2603. doi:10.1080/09585192.2016.1232294

Saludin, N., Karia, N., \& Hassan, H. (2013). Working from Home (WFH): Is Malaysia ready for digital society? Paper presented at the Entrepreneurship Vision 2020: Innovation, Development Sustainability, and Economic Growth - Proceedings of the 20th International Business Information Management Association Conference, IBIMA 2013.

Saludin, N. A., \& Hassan, H. (2012). A conceptual study on working from home in Malaysian Construction Industry. IPEDR, 56(14), 67-72.

Steward, B. (2000). Changing Times:The Meaning, Measurement and use of Time in Teleworking. Time \& Society, 9(1), 57-74. doi:10.1177/0961463x00009001004

Tang, K. H. D. (2020). Movement control as an effective measure against Covid-19 spread in Malaysia: an overview. Zeitschrift Fur Gesundheitswissenschaften, 1-4. doi:10.1007/s10389-020-01316-w

van Meel, J. (2011). The origins of new ways of working Office concepts in the 1970s. Facilities, 29(9-10), 357-367. doi:10.1108/02632771111146297

Wheatley, D. (2012). Good to be home? Time-use and satisfaction levels among home-based teleworkers. New Technology, Work and Employment, 27(3), 224-241.

Zhang, S. X., Wang, Y., Rauch, A., \& Wei, F. (2020). Unprecedented disruption of lives and work: Health, distress and life satisfaction of working adults in China one month into the COVID-19 outbreak. Psychiatry research, 112958. 